\title{
Chapter 9 \\ Being (Un)safe Together: Student Group Dynamics, Facework and Argumentation
}

\author{
Benjamin Brummernhenrich, Michael J. Baker, Lucas M. Bietti, \\ Françoise Détienne, and Regina Jucks
}

\subsection{Introduction}

Small group work offers the opportunity for students to engage in many-sided discussions. Students can learn how to argue standpoints and develop argumentative competence (i.e. learning to argue: Kuhn and Crowell 2011) but may also, by using argumentative structures, learn about and tease apart relevant facets of the topic at hand (i.e. arguing to learn: Andriessen et al. 2003; Andriessen and Baker 2014). In the DIALLS project (see Chapter 1 in this volume) for example, student groups discussed what the concept of "home" could mean. On the one hand, this brought about multiple conceptualizations of the term, especially in diverse classrooms, because students brought very different personal histories regarding living spaces and migration to the table. On the other hand, from the teacher's insistence that the students find a common definition that would encompass all those different experiences, they found out what it meant to argue a point and make sure all sides were represented in the final product.

\footnotetext{
B. Brummernhenrich $(\varangle) \cdot$ R. Jucks

University of Münster, Münster, Germany

e-mail: brummernhenrich@uni-muenster.de

R. Jucks

e-mail: jucks@uni-muenster.de

\section{J. Baker · F. Détienne}

Centre National de la Recherche Scientifique at Télécom Paris, Paris, France

e-mail: michael.baker@telecom-paris.fr

F. Détienne

e-mail: francoise.detienne@telecom-paris.fr

L. M. Bietti

The Norwegian University of Science and Technology, Trondheim, Norway

e-mail: lucas.bietti@ntnu.no
} 
Although these processes can be beneficial for both arguing to learn as well as learning to argue, their success is predicated on the characteristics of the group enacting them. Discussions happen in a social, interpersonal context. Especially in small group collaborative learning, the social relationships between students should have a stronger and more direct impact on the form and content of their contributions than in more direct, teacher-led instruction. In this chapter, we will seek to specify the relations between cognitive and social aspects of collaborative argumentation and illustrate them with an example from the DIALLS lesson recordings. These considerations will lead to a testable hypothesis: argumentation that thoroughly considers multiple perspectives thrives in social contexts in which students feel psychologically safe to provide novel viewpoints and critically engage with each other. We will also delineate methodological approaches to analyzing these different aspects empirically.

\subsection{Interpersonal Tension, Face-Threatening Acts and Politeness Strategies}

Argumentative interaction can be considered as an important test case for understanding the relations between social and cognitive dimensions of group work, given that the mutual recognition of disagreement creates interpersonal tensions (Andriessen et al. 2011), a 'problem to be solved', with respect to the task, the interaction and the interpersonal relationship. Critique of the other's proposals, expressed in a more or less aggressive manner, will usually be experienced as a critique of the person who expressed them (Muntigl and Turnbull 1998) and thereby as a threat to the recipient's face.

Politeness theory (Brown and Levinson 1987) defines face as "the positive social value a person effectively claims for himself" (Goffman 1967, p. 5), referring to a claim to certain interpersonal needs: appreciation and belonging (implying closeness to others), and autonomy (implying distance). These aspects of personal value can be threatened but also enhanced in interaction with others. This offers a useful perspective on the role of social considerations in small group discussions: students threaten their peers' face - and open themselves up to being threatened-when they are critical of what other group members do or say, face mistakes they have made themselves, tell or ask other students to show a certain behavior, or are asked to do so by others. Speech acts such as these, that represent an imposition on the recipient, are examples of face-threatening acts (for a more detailed definition see Brummernhenrich and Jucks 2013).

The relevance of face considerations in learning was first recognized from an instructor-learner relationship perspective (e.g., Kerssen-Griep 2001) but was soon extended to group learning (e.g., Chiu and Khoo 2003). In argumentative discourse, openly criticizing another student's argument, but also extending it and thus pointing out aspects that were previously lacking should be the most salient instances of 
face threats. Students can also risk threatening their own face by offering unusual perspectives that may invite ridicule.

Because all individuals endeavor to maintain their face, and because communication is by its nature cooperative (Grice 1975), people will generally try to mitigate the effect of face threats. Of course, one way to do this is to avoid face threats altogether, a phenomenon observed in one-to-one tutoring (Person et al. 1995). From this perspective, it is easy to see how face considerations can impede productive group discussions. However, it is also possible to mitigate face threats by using politeness strategies (Brown and Levinson 1987), such as hedging one's contribution ("maybe", "in a way", "if I understand correctly", etc.) and using indirect speech ("I would rather", "It would also be possible"). Another possibility is to include others ("Shouldn't we maybe", "Let's rather focus on") or to use solidarity markers.

Brown and Levinson (1987) suggested that the strategy that speakers would use depended on the "weight" of the imposition, the social distance between the interlocutors, and hierarchical differences. In a learning context, the nature and history of interpersonal relationships within the group thus plays an influential role: students who have not worked together for long will be more hesitant to be face-threatening. In groups that know each other well, this can reverse into "playful rudeness" (Ogan et al. 2012). In groups with a confrontational style, in which face threats are made routinely and bluntly, interpersonal relationships may suffer, leading to a deterioration of group members' goodwill and to less successful group work (Chiu and Khoo 2003). But whether this is so also depends on cultural discourse practices. For example, a particular culturally inscribed form of discourse in Israel known as "dugri” speech (approximately: "straight talk") welcomes open disagreement without necessarily seeking harmony or consensus (Matusov 1996). Such discourse contrasts markedly with the almost complete avoidance of overt disagreement and conflict in Japanese culture, in order to preserve group harmony, or wa (Détienne et al. 2017).

Thus, in argumentative interactions there is a fundamental paradox: the more an argumentative conflict is 'deepened', the greater will be the threat to maintaining a positive interpersonal relationship; therefore, the interaction would tend towards remaining on a more superficial level (cf. Isohätälä et al. 2017). However, such an educative interaction would risk losing its very point (i.e., deepening shared understanding of a problem). Thus, conflicts would tend to be deepened only to the extent that the interpersonal relationship would allow, which in turn implies that the best collaborative working relationship from the point of view of arguing to learn (Andriessen and Baker 2014) would be one that is sufficiently strong and 'safe' such that it allows students to take the necessary interactional risks.

\subsection{Risk Taking and Psychosocial Safety}

The concepts of team psychosocial safety, conflict norms, and group climate have been developed as group-level constructs in different fields of management, in particular organizational learning and group creativity (Paulus and Nijstad 2003). These 
constructs aim to explain or predict why some teams are more efficient than others, in particular for non-routine tasks that require knowledge elaboration, such as debates about new solutions or re-elaboration of procedures.

Team psychosocial safety is defined as a shared belief that the team is safe for interpersonal risk taking (Edmondson 1999; also compare this to the notion of a safe space, as laid out in Chapter 4 of this book). As a group-level construct, it assumes that team members share the same perception. It has to be distinguished from group cohesiveness, which can reduce willingness to disagree and challenge others' views as in the phenomenon of groupthink (Janis 1982), implying a lack of interpersonal risk taking. According to Edmondson (ibid., p. 354) "The term is meant to suggest neither a careless sense of permissiveness, nor an unrelentingly positive affect but, rather, a sense of confidence that the team will not embarrass, reject, or punish someone for speaking up. This confidence stems from mutual respect and trust among team members."

Team psychosocial safety is assumed to benefit an ongoing process of reflection and action, characterized by asking questions, seeking feedback, experimenting, reflecting on results, and discussing errors or unexpected outcomes of action (see e.g. Schön 1983, and the educational philosophy of Dewey). Edmondson's (op. cit.) analyses of work teams supported the idea that team psychosocial safety is positively associated with learning behavior in organizational work teams and that team learning behavior mediates between team psychosocial safety and team performance.

Jehn (1995) introduced the concept of conflict norms, which refers to group norms encouraging an openness to conflict and acceptance of disagreement. Related to team management and leadership style, this concept refers to elaborated norms within groups rather than shared perceptions, which are not necessarily reified as explicit rules (such as in the case of team psychosocial safety). Whereas conflicts can be detrimental for routine tasks, they tend to be beneficial for non-routine tasks, in particular when group norms promote open discussion of task issues, critical evaluation of problems and decision options (Jehn 1995).

Finally, research on group creativity has focused on the relationship between group climate and the creative process (Paulus and Nijstad 2003). Creativity involves both divergent (idea generation as broad as possible) and convergent (selection and deepening of ideas) processes. While openness of thought without overly critical debate is necessary while diverging, critical and constructive debates are necessary in converging moves. Whereas this approach has inspired methods for creativity and experimental studies testing them, other approaches based on surveys and field studies have advanced the concept of group climate, closely related to cultures of collaboration (Détienne et al. 2017), to account for better creativity and innovation in groups. West (2003) argues that group innovation requires high levels of trust between team members and a group climate characterized by participative safety.

To conclude, the concepts of team psychosocial safety, conflict norms, and group climate aim to explain differences in group performance, learning and creativity in non-routine tasks. In relation to the findings about interpersonal tension and face threats in collaborative argumentation, students' beliefs about the nature of the interpersonal relations within the group should determine how they deal with critiques, 
rebuttals, novel perspectives and other challenging situations. Empirical findings bear this out: peer acceptance seems to drive student engagement (Wentzel et al. 2020), and perceiving psychological safety is key for people to feel ready to take interactional risks (Edmondson 2003).

\subsection{Supportive and Defensive Behavior}

The novelty of our approach is to link these group-level constructs to concrete communication behaviors, as observed in task-oriented collective activities, on both the social level (i.e., face-threatening acts and supportive behaviors) but also the cognitive level (i.e., deepening and co-elaboration of knowledge). In other words, our question is: To what extent is students' willingness to engage in face-threatening communication determined by perceptions of psychosocial safety, and linked to the quality of argumentation within the group?

Communicative behaviors in the classroom can be either defensive or supportive (Gibb 1961; Garvin-Doxas and Barker 2004). Face-threatening acts from one student can lead to defensive communication in the addressee. Gibb developed a typology of behaviors that can help provide a comprehensive description of the communication 'climate' in the group. The typology consists of six categories each constituting a continuum, from defensive to supportive communication. Categories (Gibb 1961) are classified as either defensive or supportive with regards to how communicative behaviors are perceived and understood by interacting partners in dialogue.

Evaluation and description. Evaluation is a case of defensive communication because it relies on the (moral) judgment of students' ideas and opinions. It puts into question other students' performance in relation to the group activity. Description is an instance of supportive communication. It does not rely on judging students' performance but rather on the inclusion of additional information. This may involve requests to share students' feelings and more general experiences that may be relevant for the group activity.

Control and problem orientation. Control is an example of defensive communication aiming at changing students' attitudes and behaviors, based on the assumption that their performance is not appropriate. Problem orientation is supportive because it does not attempt to produce a sudden change in attitudes and behavior but rather to foster cooperation, in order to find more adequate solutions in a collaborative manner.

Strategic and spontaneous. Strategic communication is driven by the intention to manœuver students' attitudes and behaviors towards other students' and teachers' preferences. Hence, it represents a clear case of manipulative behavior in the classroom. On the other hand, spontaneous communication is not perceived to be prompted by hidden motives or selfish interests.

Neutrality and empathy. Neutrality as a communicative behavior in students and teachers may lead to the impression that other students' attitudes, behaviors and ideas are not valued or worth telling. Empathy is about understanding other students' 
beliefs, feelings and opinions and may lead to the identification with other students' experiences. Explicit understanding and identification increase trust among students and between students and teachers.

Superiority and equality. Superiority occurs when students or teachers include messages in their classroom communication that imply real or perceived higher status (e.g., power, wealth, intellectual ability and physical characteristics) compared to other students. Equality, on the other hand, appears when such differences are blurred and more horizontal forms of collaboration are perceived among students and between them and teachers.

Certainty and provisionalism. Certainty is associated with feelings of superiority. Students' and teachers' dogmatism about their attitudes, beliefs, behaviors and opinions blocks constructive dialogue and provokes a defensive reaction in other students. Provisionalism transmits openness and willingness to engage in collaborative activities, and it is essential for successful cooperation in group work.

Whether a group communicates in a predominantly supportive or defensive manner can be an additional indicator of the social climate of the group. Where face-threatening acts are unavoidable if an argument is to make progress and can only be mitigated when they become necessary, with supportive behavior there is a real choice: A disagreement can be communicated in an empathetic, provisional, problem-oriented manner, or in a seemingly neutral, but certain and controlling one. A group that shows supportive communication should be one in which the members feel psychosocially safe enough to tolerate the inevitable tension that is part and parcel of competent argumentation.

One step remains before we can fully operationalize our hypothesis, and that is to define what we mean by constructive argumentation in the sense of 'arguing to learn' and to specify which concrete argumentative strategies, visible in the group's argumentation, could be linked to interpersonal characteristics of the group as well as social aspects of their communication.

\subsection{What Is a Good Argument to Learn From?}

A main goal of dialogic classrooms is to engender high-quality argumentation. By 'high quality' here we refer primarily to argumentation that enables deepening of understanding of a problem, rather than to formal or quasi-logical validity. Students should consider multiple perspectives on a problem but also analyze each perspective critically by adding needed information and pointing out problems and suggestions for solving them.

This can be understood in terms of processes by which students "broaden and deepen" their understanding of a "space of debate" (Baker et al. 2007). The space of debate can be considered to be the set of theses that are maintained, with (counter-)arguments and systems of concepts and values underlying them as represented by a set of texts, circulating in society, studied by students as preparation for debate on socio-scientific questions. Broadening and deepening processes have 
Table 9.1 Broadening and deepening understanding of a space of debate along conceptual and argumentative dimensions

\begin{tabular}{l|l|l}
\hline & Broadening & Deepening \\
\hline Solutions/concepts & $\begin{array}{l}\text { [1] Multiplying alternative } \\
\text { solutions, ideas, theses }\end{array}$ & $\begin{array}{l}\text { [2] Discussing the meaning of key } \\
\text { underlying concepts in the } \\
\text { domain of discourse }\end{array}$ \\
\hline Argumentation & $\begin{array}{l}\text { [3] Multiplying alternative } \\
\text { (counter-)arguments for a given } \\
\text { thesis }\end{array}$ & $\begin{array}{l}\text { [4] Chaining (counter-)arguments } \\
\text { on (counter-)arguments, } \\
\text { descending in the argumentative } \\
\text { structure }\end{array}$ \\
\hline
\end{tabular}

two dimensions: (1) problem-solving solutions and concepts, and (2) argumentative. Usually the two go hand in hand, as argumentative interaction stimulates processes of meaning-making. The first dimension can also be understood in terms of the above-mentioned group creativity processes of divergence-proposing alternative ideas or solutions - and convergence (Paulus and Yang 2000)—further elaborating a given solution. Table 9.1 shows the way in which the two dimensions interact with broadening and deepening (the four cases are numbered for further reference).

A "good" argument is thus one that has sufficient deepening in the space of debate, meaning that students are considering the meanings of the key concepts and chaining arguments together, after having engaged in sufficient broadening by having considered multiple viewpoints and their arguments.

\subsection{Bringing Back the Social Context}

How do the interlocking dimensions defining the space of debate relate to social relations? It would be tempting to posit that argumentative broadening ([3], in Table 9.1) would be associated with an irenic interaction, making little threat to the interpersonal relation, and the opposite for deepening the argument ([4]). Similarly, on the level of concepts, broadening would pose no interpersonal threat, neither would deepening along this dimension ([2]).

Argumentative deepening ([4]) seems the best candidate for such a clear relation between cognition in interaction, social relations and emotions: the deeper the argument chain, the longer the conflict is pursued, the greater the threat to the interpersonal relation and the greater would be the problem of regulation of negative emotions.

However, the other cases are arguably more complex and contextual, depending on the argumentative strategies involved. Thus, multiplying alternative ideas ([1]) or discussing meanings could occur as attempts to explore, to find the best solution. They could also occur as strategic attempts to avoid losing an argument, to cloud the issue at hand, or as means to differentiate concepts from each other so that each can be 'right' (if $x$ is understood as $y$, then you're right; if it's $z$, then I'm right), 
effectively 'diffusing' a potentially face-threatening situation. These strategies are likely in groups in which students are either not familiar enough to feel safe enough to get into the thick of disputative argumentation or in groups that know each other well but are too concerned with maintaining their positive relationships.

Other specific aspects of argumentation are also relevant to social-cognitive relations. For example, use of strategic manœuvering, trying to shift the burden of proof ("It's not for me to prove the existence of God, it's for you to prove he does not exist!") could be experienced as exasperating time-wasting, claiming the other is self-contradictory could be experienced as aggressive, insisting that the other admit defeat prevents the saving of face, and of course, the use of fallacies such as certain forms of ad hominem argument shift the debate onto a negative interpersonal plane. This should only happen in groups in which students are unconcerned about the potential interpersonal fallout.

Figure 9.1 visualizes the hypothesized relationships between the social and cognitive dimensions constructs that have been discussed and a real-life example will serve to illustrate them further.

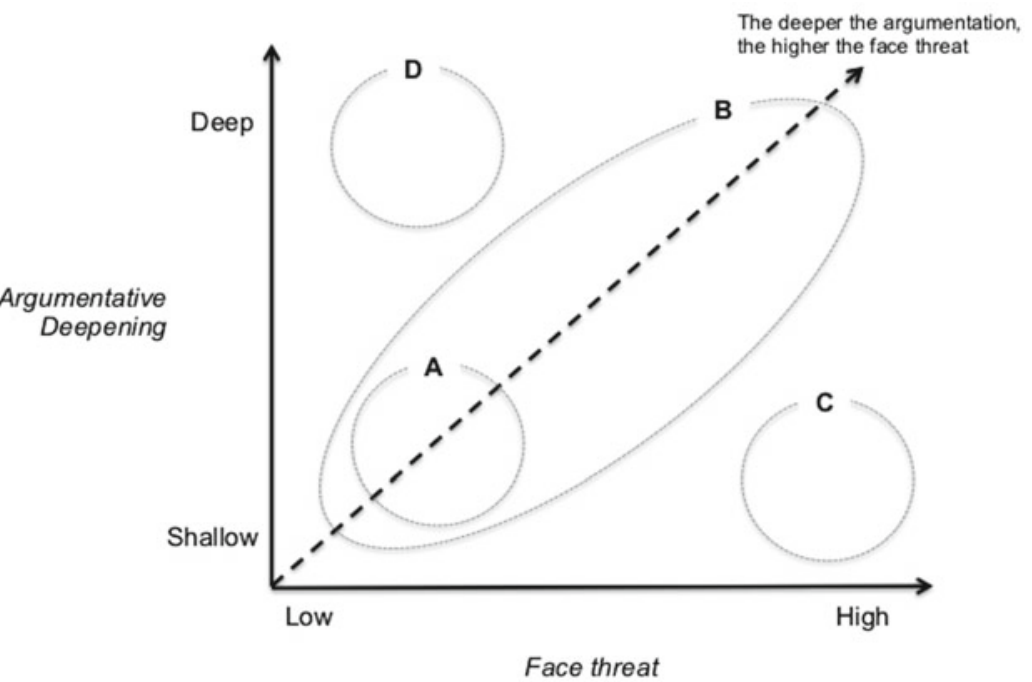

Legend: A: Group with weak interpersonal relationship and low psychosocial safety: remains in zone of shallow argumentation and low face threat

B: Group with strong interpersonal relationship: high psychosocial safety enables group to deepen argument yet bear and regulate higher face threat, moving flexibly between high/low, deep/shallow

C: Group with shallow argument yet high face threat: this corresponds to an interpersonal quarrel

D: Group that deepens argument yet manages to keep face-threatening low - e.g. with extensive use of polite redress ('it could possibly be said that ....), solidarity markers, supportive behaviour, etc.

Fig. 9.1 Visualization of the model: Relations between social and cognitive dimensions of small group argumentation 


\subsection{An Example}

The following example illustrates the methods that would enable an analysis of the kinds of relationships that our model proposes. We try to highlight instances of broadening and deepening of arguments as a content-related, cognitive aspect as well as markers of social aspects of the interaction: politeness strategies and face threats, as well as supportive and strategic interaction.

The following excerpt comes from a group of four students in a German ninth grade classroom. The students are working in small groups and discussing the wordless cut-paper leporello book "Excentric City", depicting several city scenes with people engaged in diverse, sometimes fantastical, sometimes commonplace activities, such as sitting at a desk writing something or sitting on the back of a large bird-like animal. The aim of the lesson is for students to grasp the meaning of the concept of diversity.

In the excerpt shown below, the four 14-15 year old girls have been discussing the question "How are people different?" S3 has been tasked with writing down the results of the discussion for later presentation to the class. S4 is currently absent. The excerpt starts with $\mathrm{S} 2$ stating the question again:

S2 What other differences can there be between people?

S3 Appearance.

S2 That's not at all important though is it, actually.

S3 Yeah, or rather skin color $\{$ can be $\}$ different.

S2 NO.

S3 Yes, in the past they differentiated based on that.

S2 Yeah, in the past, but we're not in the past.

S3 But still, anyway. I'll write in brackets.

S2 That's racist, S3. It's not as if they're different people.

S3 Yes, now I have already put a bracket there. Then tell me something else that I can write.

S2 Although it's not actually racist. It's just-

S3 Yeah, that's why, yeah.

S2 Yeah, but you shouldn't DIFFERENTIATE between people based on their skin color.

S3 Yes, but some people differentiate them like that anyhow.

S2 Yes, but if we don't write it down, then perhaps it's not like that (laughs), you know?

S3 No, it's still like that. I don't know how to say it.

S2 That makes no sense.

(S4 returns to the table prompting some off-task discussion)

S2 Yes, what are the differences?

S4 What have you written?

S2 Yes, but they're not simply other people just because they have a different skin color.

S4 Look, a dark egg, a white egg, but inside they all look the same.

S2 YES. (S2 and S4 high five and laugh) 
S3 Ah, okay. That wasn't even funny.

S2 I wouldn't write that about the skin color (points to the piece of paper), are you different to me just because we have different skin? Skin color doesn't matter one bit. When you've been to Majorca, you're brown too.

S3 Yeah. Then I'll say hair color.

S2 NO.

S4 No, don't do that.

S2 (pushes S3's pencil from the paper and takes out some tipp-ex to remove what she's written)

On the content level, the students are debating whether appearance is a meaningful category for distinguishing people. After S3's initial proposal S2 disagrees immediately. This prompts S3 to suggest skin color as a specific instance of appearance. They then go back and forth, basically repeating arguments without going much deeper on them: some people do differentiate based on skin color (S3's point) but they should not (S2). S4 seems to add the clinching detail to S2's side by providing the "egg analogy". In summary, we see some slight deepening of arguments and counterarguments [4], possibly constrained by the students' (in)ability to express their thoughts.

On the interpersonal side this development is paralleled by heightening social tension: The discussion already starts off as a confrontation between S2 and S3 but the disagreements are nearly always mitigated by politeness strategies, especially "Yeah, but ..." (i.e., agreeing but disagreeing). As the discussion progresses, there are increasing instances of very direct, unmitigated face threats: "That makes no sense," "That wasn't even funny," "No, don't do that." and the fact that S2 prevents S3 from writing on the paper. This type of controlling communication from S2 will reoccur in the course of the discussion. Especially S2 and S3 are continuously engaging in socially risky behavior by insisting on their own standpoints and contradicting the other's.

It is telling, then, that after this episode the students move away from the topic for a while and talk about their mutual dislike for another student in the class instead. This can be seen as an attempt to "get back into the green" and ease the tension that has arisen (Baker et al. 2013). It is also important to know that the group has been joking together before and will do so again in the next part. This could be an indicator that the possibility of tenaciously arguing out contentious points is afforded by a secure interpersonal relationship, whose 'signature' corresponds to the specific way in which facework and argumentative deepening 'play out' in the interaction.

After the short off-topic intermission, the group returns to the topic with S2, again, restating the question:

S2 So, what are the differences between different people?

S4 Character.

S2 What?

S3 Exactly.

S2 Different ways of thinking (points to the piece of paper for S3 to write it down).

S4 Hear, hear. 
S2 Different opinions.

S1 Haha, like you and $\{\mathrm{S} 3\}$.

S2 Oh, now it's getting personal here. We don't want that [...] Uh. Do we have different interests, we do, don't we? Hm and, um, what makes YOU different from $\mathrm{S} 14$ (to $\mathrm{S} 1$ )?

S1 Girl, boy.

S2 Yes, yes.

S1 [Guys, hey, I'll tell you something. So, actually] we're not all that different, all his marks are as bad as mine, we're both dumb.

S2 Brain cells (laughs).

S3 Stupidity (laughs).

S4 And cleverness.

S2 What else? Age.

S3 Yes (writes).

S2 Don't always make a new dash straight away (to S3), otherwise we won't have any more ideas later on and there'll be a line there.

S3 Then don't write anything.

S1 Yeah, but S2 always has to have everything neat.

S2 And you're crumpling the paper at the bottom (takes the piece of paper).

S3 It's already crumpled now.

S2 No.

S3 It is.

S4 Oh he he he. Hey, hey, hey. Fingerprint as a thingy, there are different ones.

S3 Ah, right (wants to write).

S2 Nope (holds the pen tightly).

S3 DNA.

\section{S4 IDENTITY.}

Content-wise, this is clearly on the side of broadening concepts [1]: The group simply enumerates concepts that could fit the question. They are thus offering diverging views on the subject matter but there is no arguing about their validity, only about S3's handling of the paper and writing.

Accordingly, this part of the discussion starts off in a much calmer manner than the last. There is no confrontation and there are no face threats to speak of until shortly before the end, and quite a bit of joking and laughing together (including former opponents S2 and S3). However, tensions return when S2 makes it clear, in a face-threatening manner, that she is unhappy with S3's writing, showing a controlling stance. She is in turn mocked for it ("S2 always has to have everything neat"). S2 again prevents S3 from writing, but the mood is generally more joking than before, and most face threats are mitigated, however the discussion is also on a much shallower level. This changes again in the last part of the example when the concept of identity is elaborated:

S2 What is identity exactly?

S3 It's exactly the same as DNA.

S4 It's what makes you who you are. 
S2 NO (to S3).

S4 It's what makes you who you are. TRUE.

S2 Identity?

S4 Name and that kind of thing.

S2 Crazy that we still don't even know what an identity is.

S3 Identity is when a person, um- You have an identity, everyone alive has an identity, when you-

S2 Yes, I know.

S4 Here people-

S2 S1. What is the difference between you and Mrs XY?

$\mathrm{S} 1 \mathrm{Mrs} \mathrm{XY}$ is a teacher and I'm not.

S2 EDUCATION.

S4 No, no, roles, roles. Everyone has different roles.

S3 (To S4) Shh, be quiet.

S4 Everyone has different roles, we learned that in German class.

S3 Lol.

S4 Put it together now.

S3 That's what I'm doing.

S2 NO.

S3 Yes, I am (wants to write).

S2 She has to explain it first (holds the pen tightly).

S4 Roles. Everyone has different roles. At home you're the child that comes home. At school you're the pupil.

S1 Okay, I'll write.

This looks like a case of conceptual deepening [2]: The group argues the meaning of the concept "identity" by identifying subordinate concepts, such as names and roles. There is an interesting bit of metacognitive awareness, and thus problem orientation, when S2 realizes that it is "crazy that we still don't even know what an identity is." S4's suggestion of the concept of roles is not acknowledged immediately so she has to elaborate it until S1 finally takes it up.

$\mathrm{S} 2$ seems to be in a confrontational state of mind by now, uttering direct face threats ("NO") and holding onto S3's pen again. Her asking S1 about the difference between her and a teacher seems like strategic instead of spontaneous, supportive communication. But her insistence also induces S4 to make the concept of role clearer by adding another example: The socially risky behavior leads to (some) more deepening.

In summary, the excerpt shows a diverse range of argumentative as well as interpersonal behaviors. Our analysis also suggested ways in which the two may be intertwined: Phases of confrontational, face-threatening communication co-occur with progress in deepening arguments and concepts. However, this is only possible because the group seems to share a sense of psychosocial safety which rises to the surface in episodes of joking and supportive, but also less argumentatively progressive communication. 


\subsection{Concluding Discussion}

How do interpersonal characteristics of a student group impact the epistemic quality of their argumentation? We propose that broadening and deepening the space of debate entails interpersonal risks. The willingness to take these risks and threaten one's own or other's faces depends on perceived psychosocial safety. If students feel valued and evaluate their interpersonal relationship with other group members as stable and positive, it will be easier for them to "go out on a limb" and present novel perspectives or critiques. As explained in Chapter 4 of this book, a group that is a (psychosocially) safe space is also a necessary prerequisite for successful and empathic intercultural dialogue. The examples illustrate some of these processes.

How can these relations be operationalized? When analyzing transcripts of smallgroup discourse, positive relationships within the group should be evident in the way students interact with each other, through supportive behaviors between the group members. Perceived psychosocial safety cannot be observed directly from the interaction alone. However, how the group deals with potential face threats, how willing they are to take interactional risks can be a proxy for how students feel about working in the group: how many face threats are made, relative to the number of total turns? If face-threatening acts appear, how many are mitigated by politeness strategies or uttered without redress? And finally, broadening and deepening can be analyzed by enumerating the different viewpoints that the group considers, whether terms are defined and argued, and the way in which arguments relate to each other, accumulating in a linear way, or else in a 'descending' structure of arguments on arguments. In our example, we took a qualitative methodological approach that allows in-depth insights into single interactions. However, quantitative approaches would also be viable, such as calculating the ratio of unmitigated face threats in an interaction and comparing this between discussions of differing argument quality.

However, it is unreasonable to assume a linear relationship between the three variables (supportive behavior in the group, risk-taking or face-threatening acts, and the quality of the students' argumentation). Certainly, negative relationships will lead to distrust and the unwillingness to make oneself vulnerable by offering a personal view, or alternatively to overly confrontational interactions where no empathetic perspective-taking occurs. However, a certain degree of tension and its regulation is needed for productive discussion.

A high ratio of positive affect and supportive behavior and few face threats might indicate a group focusing too strongly on relationship management, rather than working on a deep and multifaceted argument. In contrast, very frequent occurrences of blunt, direct face-threatening acts should be a sign of negative relationships, but the absence of face-threatening acts is also a bad sign as it signals that students are not comfortable to expose themselves. In a well-working group, we should see a rather high amount of face-threatening acts, but most of which should be mitigated by politeness strategies, excluding maybe some cases of "playful rudeness", going along with both broadening and deepening of the argument. 
The DIALLS data offer a view into the discussions of student groups in very diverse classrooms and age groups all over Europe and Israel. The amount of variation that is likely to be seen in these discussions, along with the theoretical considerations and operationalizations of this chapter, will allow the testing of the hypotheses regarding the relationship between social and cognitive aspects of argumentation.

This will open up exciting possibilities for educational and learning research, such as analyzing the specific impact of online environments for argumentation (see Chapter 7, this book), a context that grows only more pertinent in a post-COVID-19 world. But it will also provide fuel for practical considerations: how can teachers and instructors engender contexts in which stable, safe relationships afford high-quality argumentation? We argue that fostering deep learning necessitates providing for one of the most basic human needs, the desire for positive social contact.

\section{References}

Andriessen, J., and M. Baker. 2014. Arguing to learn. In The Cambridge handbook of the learning sciences, ed. R. K. Sawyer, 439-460. Cambridge: Cambridge University Press. https://doi.org/ 10.1017/CBO9781139519526.027.

Andriessen, J., M.J. Baker, and D. Suthers. 2003. Arguing to learn: Confronting cognitions in computer-supported collaborative learning environments. Dordrecht: Kluwer Academic Publishers. https://doi.org/10.1007/978-94-017-0781-7.

Andriessen, J., M. Baker, and C. van der Puil. 2011. Socio-cognitive tension in collaborative working relations. In Learning across sites: New tools, infrastructures and practices, ed. S. Ludvigsen, A. Lund, I. Rasmussen, and R. Säljö, 222-242. New York: Routledge.

Baker, M., J. Andriessen, and S. Järvelä. 2013. Affective learning together: Social and emotional dimensions of collaborative learning. New York: Routledge.

Baker, M., J. Andriessen, K. Lund, M. van Amelsvoort, and M. Quignard. 2007. Rainbow: A framework for analysing computer-mediated pedagogical debates. International Journal of Computer-Supported Collaborative Learning. https://doi.org/10.1007/s11412-007-9022-4.

Brown, P., and S.C. Levinson. 1987. Politeness: Some universals in language usage. Cambridge: Cambridge University Press.

Brummernhenrich, B., and R. Jucks. 2013. Managing face threats and instructions in online tutoring. Journal of Educational Psychology. https://doi.org/10.1037/a0031928.

Chiu, M.M., and L. Khoo. 2003. Rudeness and status effects during group problem solving: Do they bias evaluations and reduce the likelihood of correct solutions? Journal of Educational Psychology. https://doi.org/10.1037/0022-0663.95.3.506.

Détienne, F., M. Baker, M. Vanhille, and C. Mougenot. 2017. Cultures of collaboration in engineering design education: A contrastive case study in France and Japan. International Journal of Design Creativity and Innovation 5: 104-128.

Edmondson, A. 1999. Psychological safety and learning behavior in work teams. Administrative Science Quarterly. https://doi.org/10.2307/2666999.

Edmondson, A.C. 2003. Managing the risk of learning: Psychological safety in work teams. In International handbook of organizational teamwork and cooperative working, ed. M.A. West, D. Tjosvold, and K.G. Smith, 255-275. Chichester, UK: Wiley.

Garvin-Doxas, K. and L.J. Barker. 2004. Communication in computer science classrooms: Understanding defensive climates as a means of creating supportive behaviors. Journal of Educational Research in Computing. https://doi.org/10.1145/1060071.1060073. 
Gibb, J. R. 1961. Defensive communication. Journal of Communication. https://doi.org/10.1111/j. 1460-2466.1961.tb00344.x.

Goffman, E. 1967. Interaction ritual: Essays on face-to-face interaction. Oxford: Aldine.

Grice, H.P. 1975. Logic and conversation. In Syntax and semantics, vol. 3, ed. P. Cole and J. Morgan, 41-58. New York: Academic Press.

Isohätälä, J., P. Näykki, S. Järvelä, and M. J. Baker. 2017. Striking a balance: Socio-emotional processes during argumentation in collaborative learning interaction. Learning, Culture and Social Interaction. https://doi.org/10.1016/j.lcsi.2017.09.003.

Janis, I.L. 1982. Groupthink: Psychological studies of policy decisions and fiascoes, 2nd ed. Boston: Houghton Mifflin.

Jehn, K.A. 1995. A multimethod examination of the benefits and detriments of intragroup conflict. Administrative Science Quarterly. https://doi.org/10.2307/2393638.

Kerssen-Griep, J. 2001. Teacher communication activities relevant to student motivation: Classroom facework and instructional communication competence. Communication Education. https://doi. org/10.1080/03634520109379252.

Kuhn, D., and A. Crowell. 2011. Dialogic argumentation as a vehicle for developing young adolescents' thinking. Psychological Science. https://doi.org/10.1177/0956797611402512.

Matusov, E. 1996. Intersubjectivity without Agreement. Mind, Culture and Activity. https://doi.org/ 10.1207/s15327884mca0301_4.

Muntigl, P., and W. Turnbull. 1998. Conversational structure and facework in arguing. Journal of Pragmatics. https://doi.org/10.1016/S0378-2166(97)00048-9.

Ogan, A., S. Finkelstein, E. Walker, R. Carlson, and J. Cassell. 2012. Rudeness and rapport: Insults and learning gains in peer tutoring. In Intelligent tutoring systems, vol. 7315, ed. S. Cerri, W. Clancey, G. Papadourakis, and K. Panourgia, 11-21. Berlin: Springer. https://doi.org/10.1007/ 978-3-642-30950-2_2.

Paulus, P.B., and B.A. Nijstad. 2003. Group creativity: Innovation through collaboration. New York: Oxford University Press.

Paulus, P. B., and H.-C. Yang. 2000. Idea generation in groups: A basis for creativity in organizations. Organizational Behavior and Human Decision Processes. https://doi.org/10.1006/obhd.2000. 2888.

Person, N.K., R.J. Kreuz, R.A. Zwaan, and A.C. Graesser. 1995. Pragmatics and pedagogy: Conversational rules and politeness strategies may inhibit effective tutoring. Cognition and Instruction. https://doi.org/10.1207/s1532690xci1302_1.

Schön, D.A. 1983. The reflective practitioner: How professionals think in action. New York: Basic Books.

Wentzel, K. R., S. Jablansky, and N. R. Scalise. 2020. Peer social acceptance and academic achievement: A meta-analytic study. Journal of Educational Psychology. https://doi.org/10.1037/edu000 0468.

West, M.A. 2003. Innovation implementation in work teams. In Group creativity: Innovation through collaboration, ed. P.B. Paulus and B.A. Nijstad, 245-276. New York: Oxford University Press.

Benjamin Brummernhenrich is a Senior Faculty Member at the Institute of Psychology for Education at the University of Münster in Germany. He researches the interplay of social processes and content in the communication between learners and instructors in diverse educational contexts.

Michael J. Baker is a tenured Research Professor in language sciences of the Centre National de la Recherche Scientifique at Télécom Paris. His research aims to understand the processes of collaborative learning and work, drawing on dialogue and argumentation analysis. 
Lucas M. Bietti is an Associate Professor in psychology at the Norwegian University of Science and Technology. He holds an honorary affiliation with Centre National de la Recherche Scientifique at Télécom Paris.

Françoise Détienne is a tenured Research Professor in cognitive ergonomics of the Centre National de la Recherche Scientifique at Télécom Paris. Her research focuses on technologymediated collaboration, co-design and online epistemic communities.

Regina Jucks is a Full Professor at the Institute of Psychology for Education at the University of Münster. Her research fields address various settings of instructional communication ranging from doctor-patient interaction to higher education.

Open Access This chapter is licensed under the terms of the Creative Commons Attribution 4.0 International License (http://creativecommons.org/licenses/by/4.0/), which permits use, sharing, adaptation, distribution and reproduction in any medium or format, as long as you give appropriate credit to the original author(s) and the source, provide a link to the Creative Commons license and indicate if changes were made.

The images or other third party material in this chapter are included in the chapter's Creative Commons license, unless indicated otherwise in a credit line to the material. If material is not included in the chapter's Creative Commons license and your intended use is not permitted by statutory regulation or exceeds the permitted use, you will need to obtain permission directly from the copyright holder.

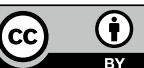

